\title{
Information systems in geotechnics
}

\author{
Aleks Diveev, and Gennadii Boldyrev* \\ Penza state university of architecture and construction, 440028 Penza, Russia
}

\begin{abstract}
The article considers the information modeling of buildings together with the foundation within the information system and the stages of its implementation. The workflow for building a 3D geotechnical model includes surface relief data, field and laboratory test data, soil lithology, geometric characteristics of the foundation structure and load. Automated systems with processing and interpretation of test data are used to determine the characteristics of soils. Mathematical modeling of the behavior of the foundations of the foundations with various input data is performed using analytical solutions and numerical methods. The natural heterogeneity of soil properties and its impact on the behavior of buildings is estimated by the sensitivity indicator of the foundation-foundation system by introducing virtual workings between the existing normative ones and the subsequent calculation of the precipitation and roll of the foundation.
\end{abstract}

\section{Introduction}

The widespread use of information modeling in construction (BIM-Building Information Modeling) is mainly due to the advantages in terms of saving costs and time for the implementation of the project, due to the reduction of unforeseen problems and easier updating of the digital model. Thanks to technical research conducted by universities and industry, useful tools have been developed to optimize digital models and improve interaction between various specialists involved in the design process [1].

Building information modeling is widely used by civil engineers and architects for designing structures of buildings. At the same time, it may sound paradoxical, geological and geotechnical data are not used at all in the BIM design process, although most of the risks and uncertainties of construction arise from unknown or incorrectly estimated engineering and geological conditions. At the moment, BIM technologies are being developed for many sections of the design and construction, with the exception of engineering-geological and geotechnical surveys.

Unfortunately, not so many geotechnical projects have yet been implemented using the BIM approach, and in most cases, it still consists only in archiving, storing and updating geological and geotechnical data [2,3]. However, in the last two years, the situation has changed and there have been works that consider the methodology of building information systems in geotechnics $[4,5]$.

\footnotetext{
*Corresponding author: g-boldyrev@geoteck.ru
} 
This article demonstrates the applicability of the developed technology to the entire process of designing the foundations of construction objects, starting with engineeringgeological, engineering-geotechnical surveys and ending with the calculation of the foundations of foundations using appropriate sets of rules or numerical methods. The advantage of automated testing methods and mathematical modeling of foundation bases based on known values of physical and mechanical properties of soils at normative and virtual workings is emphasized.

\section{Basic concepts and definitions}

Basic definitions. The initial data for the construction of a digital information geotechnical model is an engineering-geological model, which is a schematic spatial representation of engineering-geological elements (IGE), groundwater, hazardous geological and engineering-geological processes in the field of interaction of the object with the geological environment. This definition is given in SP 446.1325800.2019 "Engineering and geological surveys for construction. General rules for the production of works" and is incomplete, so it does not include the properties of soils in the IGE, despite the fact that the survey results include data on the physical and mechanical properties of soils. The proposed geotechnical information System (BIMG) has a more extended definition:

1. BIMG (Building Information Model Geotechnical) is a digital information model with a set of components that characterize stratigraphy and lithology, physical and mechanical properties of soils and the construction of the foundation in three-dimensional space.

2. BIMG-contains the information necessary for the design of the foundations of buildings and structures according to the limit states and is one of the information models that make up the BIM of a construction object.

3. The development and development of BIMG is carried out in a shared data environment, which means that all interested parties have constant access to a model filled with information from surveys at the construction site.

4. BIMG uses three approaches to modeling: geostatistical, explicit and numerical modeling. For all approaches, data is collected, quality-controlled, transformed (if necessary), harmonized, classified and interpreted. Modeling begins only after the input data has successfully passed the processing and quality control processes.

In order to eliminate confusion in the concepts of "geological model" and "geotechnical model", we will introduce additional explanations.

The 3D geotechnical model is created by geostatistical methods based on workings, surface maps and engineering-geological sections. It is important that the source data used is uniformly classified and consistent. The choice of the geostatistical method, scale, and other parameters of the model depends on various criteria, such as the parameter to be modeled, the scale of the model, the complexity of engineering and geological conditions, and the distribution of input data. To validate the implemented 3D models, various checks are carried out: visual checks, variogram analysis and cross-validation. Automation of data processing and interpretation processes ensures the relevance of models and the ability to track their development. That is why it is extremely important to automate as many stages of the workflow as possible.

The 3D geotechnical model is created on the basis of a 3D geological model by introducing additional information about the design of the projected foundation, external loads on the foundation, as well as the parameters of soil models necessary for calculating the foundations of foundations by numerical and analytical methods. 


\section{Methodology of building a geotechnical information system}

The procedure for creating a geotechnical information system (BIMG) is a workflow consisting of the following main stages:

1) the surface relief of the construction site under consideration is determined using GIS systems.

2) a complex of laboratory and field tests of soils is carried out using automated complexes at standard workings. Here and further in the text, mining is understood as a geological well with the selection of monoliths or a point of static or dynamic sounding;

3 ) the stratigraphy and lithology, physical and mechanical characteristics of soils are determined. In the case of using numerical methods, the parameters of soil models are determined;

4) a 3D geological model is being built;

5) a geotechnical 3D model is formed by dividing the geological model into finite elements of a given scale and the coordinates of their nodes X,Y,Z are determined;

6) using the interpolation functions (for example, Shepard, Delaunay, Kriging, etc.) and the values of soil characteristics at standard workings, the soil characteristics (parameters of soil models) are found in finite elements;

7) the foundation structure and loads are introduced into the 3D model;

8) the foundation is calculated using analytical solutions of the corresponding sets of rules or numerical calculation methods;

9) virtual workings are introduced and the influence of heterogeneity of soil properties on the results of analytical or numerical solutions is evaluated;

10) To transfer information to the external environment, a $3 \mathrm{D}$ digital geotechnical model is produced in the IFC4 format, which allows it to be used in 3D programs such as Civil 3D, Revit, Allplan, Flac, Plaxis, etc.

Geotechnical data. Engineering-geological and geotechnical studies performed by geotechnical engineers or geologists are the main way to obtain geotechnical data that carry information about stratigraphy, lithology, physical and mechanical properties of soils and rocks at the survey site. Geotechnical data are of crucial importance in the design of the foundations of buildings and structures and the construction of transport infrastructure facilities.

Standard geotechnical data is collected from three main sources: (1) wells and pits; (2) in situ tests, including geophysical surveys, static (CPT) and dynamic sounding (SPT) tests, etc.; and (3) laboratory tests conducted on samples taken from wells. Some geotechnical data can be collected from pits or tests at the bottom of pits. However, they make up a small percentage of the data compared to well data and are usually processed in the same way.

For laboratory testing of soils, the automated ASIS Lab system has been developed, which includes various devices for static and dynamic testing of unfrozen and frozen dispersed soils, rocks. Field tests are carried out using various methods, such as cone penetration test, standart penetration test, dilatometer test, pressiometer test, etc. The interpretation of field test data is automated and is performed using the «Geotek Field» program.

Data maps. Data maps in the form of a situational plan of engineering-geological and geotechnical studies (Fig. 1) describe the type of data (geophysical studies, field tests with stamps, static and dynamic penetration, etc.) available for each IGE in the model. Although these maps do not convey the reliability of the geological model, they give a very clear idea of what type of data contributed to each IGE and what is the data density in this area of the model. Based on the information obtained from the data maps, the user can quickly recognize areas studied by mathematical modeling (virtual workings) and areas based on measured data (standard workings). For example, in Fig. 1, at object 4A-8, drilling wells 
and static penetration were performed at four points (standard workings, cone penetration tests) and 13 virtual workings (V1-V13) were constructed using the interpolation functions, in which the lithology and soil properties were determined.

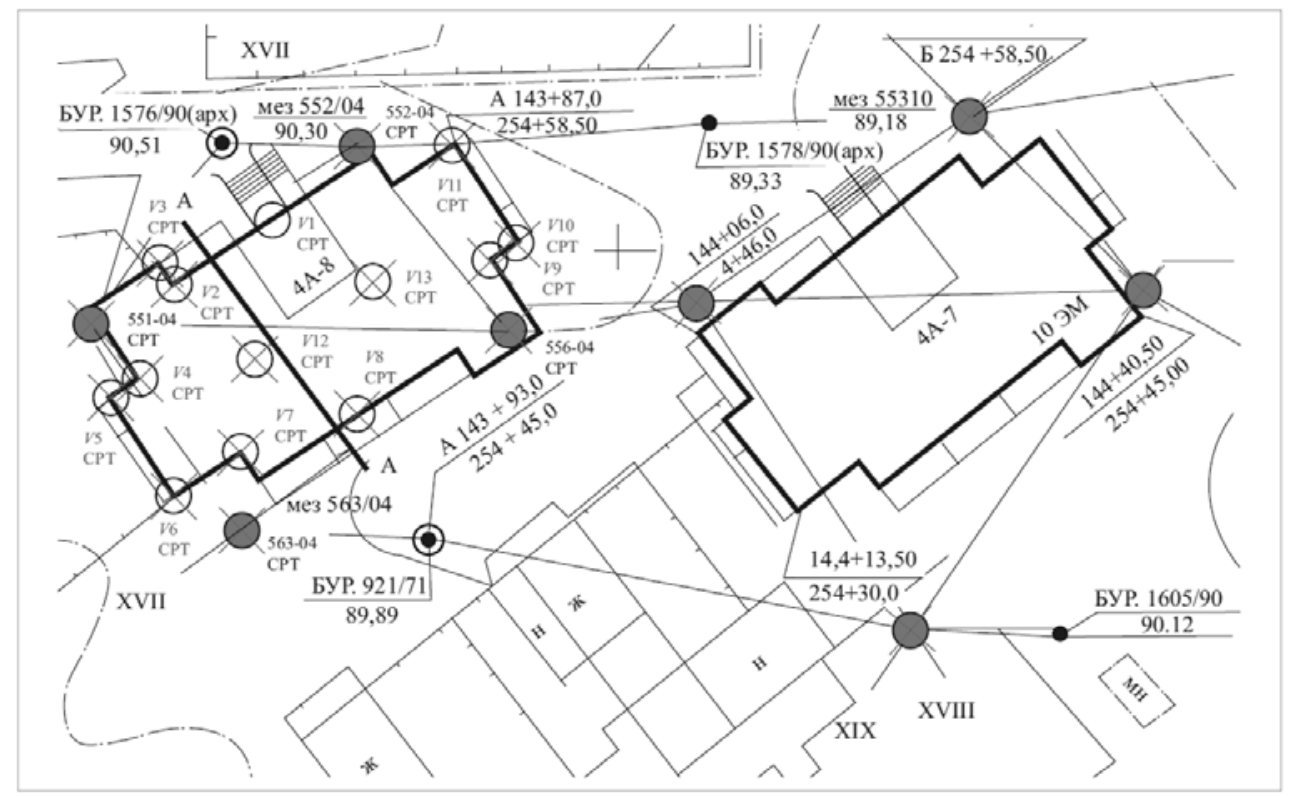

Fig. 1. Survey data map with building plans.

The scale and detail with which a geotechnical model can be built are inherently related to the density and detail of data obtained from engineering-geological and geotechnical investigations. The amount of data depends on the stage of surveys and the category of complexity of engineering and geological conditions, which are determined by the regulatory requirements of SP 47.13330.2012 " Engineering surveys for construction. Main provisions": the stage of choosing a construction site; the stage of preparing project documentation; the stage of construction and reconstruction of buildings and structures; and three categories of complexity of engineering and geological conditions. For example, for the stage of preparation of project documentation, the distance between the normative workings depends on the complexity category of engineering and geological conditions and varies from 25 to $100 \mathrm{~m}$. The total number of mine workings within the contour of each building and structure for category I is 1-2 workings; for category II-at least 3-4, for category III - the number of mine workings is determined by the design of a specific foundation, loads on the base and engineering and geological conditions, but not less than 4-5, taking into account the geometric dimensions of the object. With such a meager density of workings, it is quite difficult to assess the heterogeneity of soil properties and their influence on the behavior of the projected building or structure.

Data processing and interpretation. The use of all available data from the workings involves the use of automated interpretation procedures due to the huge amount of available data. We have created a set of tools to provide a standard method for processing laboratory data, cone penetration test (CPT) and standard penetration test (SPT) data. With the help of this tool, we can interpret the lithology in the workings, using their position in the direction of the XY and $\mathrm{Z}$ coordinates of the three-dimensional soil array. The lithology inside the geotechnical model is determined by simple processing of CPT parameters (cone resistance, coefficient of friction, depth, see Fig. 3,4) using P. Robertson diagrams [6], and the physical and mechanical characteristics of soils are found from correlation equations 
connecting them with the parameters of static (CPT) and dynamic sounding (SPT) [11]. By applying automated procedures, we can use more data than ever before. This allows us to create more detailed geotechnical models.

Currently, BIMG includes data from laboratory tests, CPT, CPTU, SPT, DCPT in situ tests, performs a basic interpretation from the point of view of the behavior of the soil type [6], determines the physical and mechanical characteristics of soils and calculates the foundations of buildings and structures in accordance with the requirements of the codes of regulations of the Russian Federation SP 47.13330-2012 "Engineering surveys for construction. Basic provisions", SP 24.13330.2011 "Pile foundations", SP 22.13330.2016 "Foundations of buildings and structures", SP 25.13330.2012 "Base and foundations on permafrost soils" or foreign regulatory technical documents EN 1997-1 "Eurocode 7Geotechnical Design-Part 1: General rules", etc.

When determining the physical and mechanical characteristics of soils, correlation dependencies are used (for example, SP 446.1325800.2019) between the parameters measured during static and dynamic penetration and the data of laboratory tests of soils. Using the sounding parameters and correlation equations, the physical and mechanical characteristics of soils are determined.

The IFC4 format is used to transmit information to an external user. The IFC4 format was developed by buildingSMART in 2013 specifically for building information modeling, approved by the international standard ISO 16379 and recommended by GOST 10.0.022019 for use in the Russian Federation. The format file has a text structure corresponding to the STEP file (ISO 10303-21 international standard for CAD data exchange), which borrows a model of entity relationships from the EXPRESS data modeling language. Such entities are: building elements, geometry, basic constructs. Entities form an object hierarchy with property inheritance. At the moment, there are more than 700 such entities. The format is extensible, if the required building element is not described, then it is possible to add your own.

No special entities have been created yet to create a digital geotechnical model. This is due to the lack of a format for the exchange of engineering and geological data in the Russian Federation at the moment. The authors use the entities IfcBuildingElementProxy and IfcPropertySet to build such a model. The first entity contains a geometric description of the surfaces, coordinates, color, and the name of the type of soil. The second one is responsible for storing the physical and mechanical characteristics of soils

$2 D$ and $3 D$ visualization. An example of a three-dimensional visualization of a geological model is shown in Fig. 2 (cross-section section A - A in Fig. 1) together with the construction of a slab foundation. The 3D modeling and visualization provides a powerful tool for spatial analysis. The purpose of visualization is to use a $3 \mathrm{D}$ model that can receive different scales of information from different sides and in sections. Visualization includes standard and virtual workings, lithological columns, profiles of physical and mechanical characteristics of soils, the position of the groundwater level, the foundation structure.

Knowing the values of the soil characteristics in the standard workings, you can build virtual workings and then use the obtained values of the characteristics in calculations (for example, the calculation of the settlement and the tilt of the foundation according). You can build as many virtual workings as you want, and their impact can be estimated by the amount of the determined foundation precipitation. The main rule for choosing the number of virtual workings is determined by the rule for stabilizing the increment of the average foundation settlememnt as they are introduced. In Fig. 3 shows an example of constructing a field of values of the deformation modulus for two standard workings and with the introduction of two virtual workings. In this example, the Kicking interpolation function is applied. As can be seen from the example considered, the use of the interpolation function allows you to build a digital array of the required soil characteristics. 


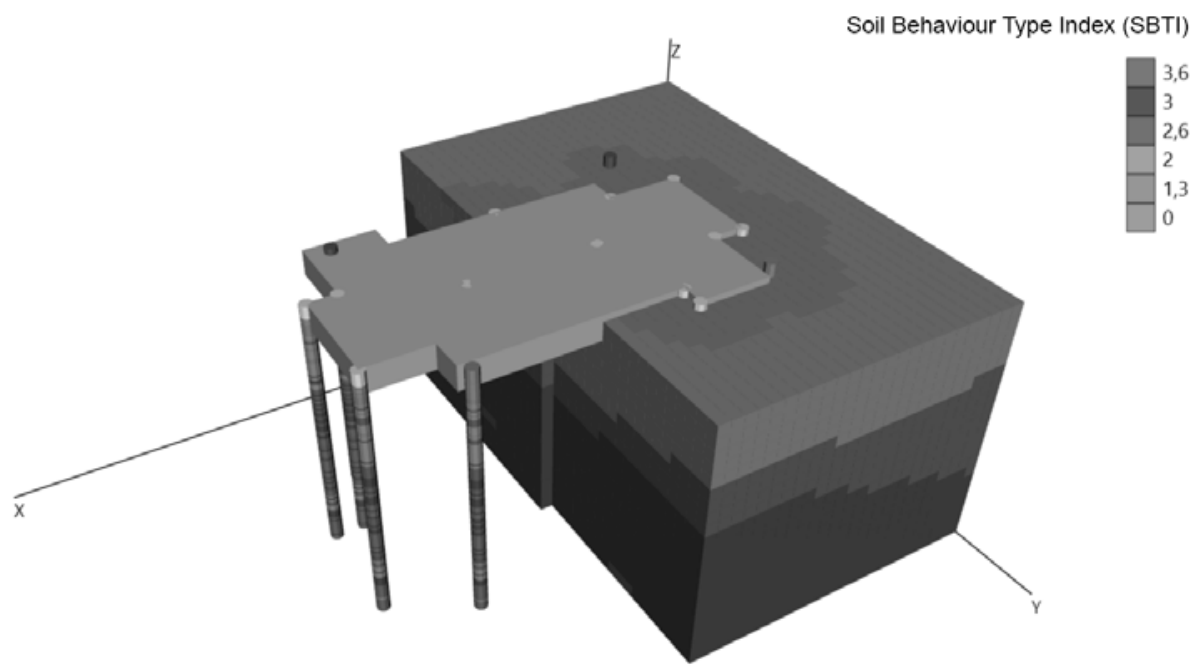

Fig. 2. An example of 3D visualization of a geotechnical model with a foundation structure, virtual and standard workings.

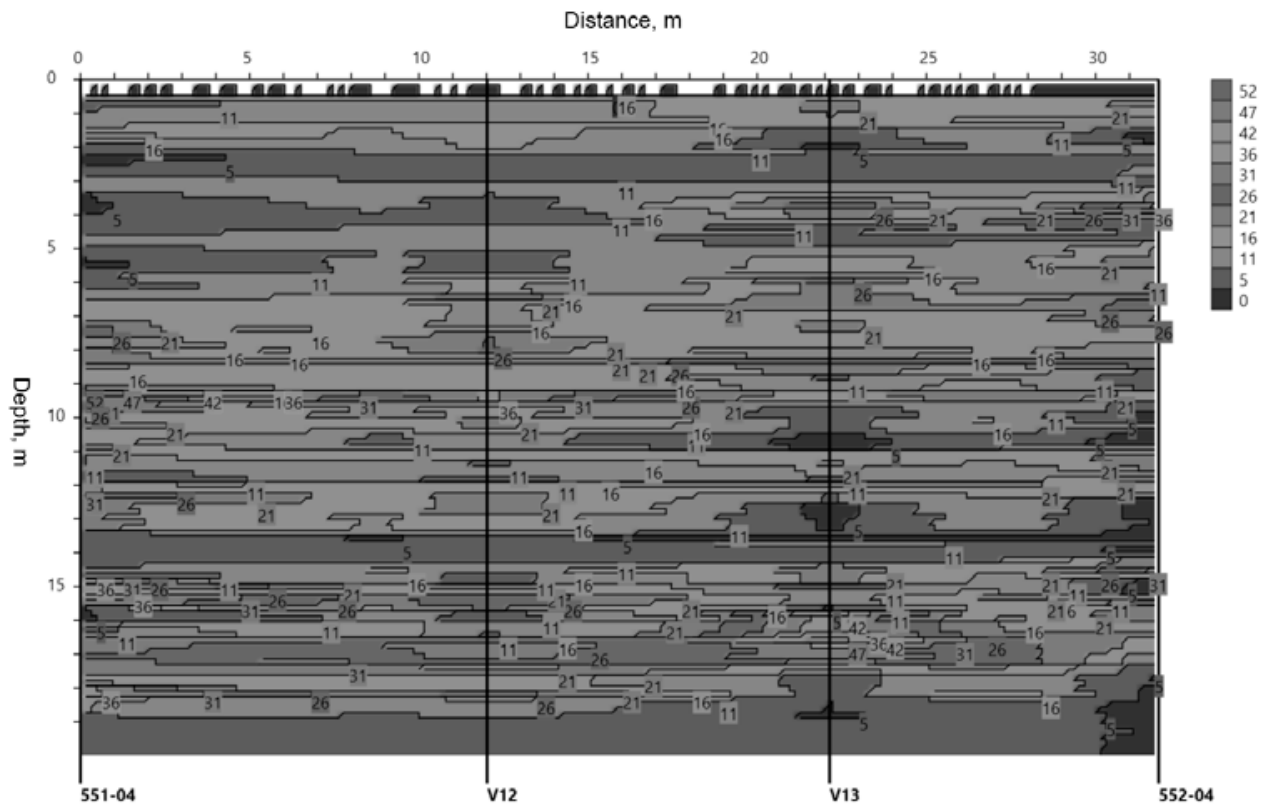

Fig. 3. 2D distribution of the deformation modulus: 551-04, 552-04 - standard workings; V12, V13 virtual workings.

It should be noted that the considered procedure is performed automatically, directly in the process of static sounding of soils, and since it is possible to perform sounding not in four, but in a larger number of points during a working shift, the accuracy of estimating the heterogeneity of engineering and geological conditions will be significantly higher.

Calculation of the foundation bases. Currently, the foundations of buildings and structures are designed using analytical and numerical solutions. Analytical solutions are simple, easily programmable, require determining the minimum number of soil 
characteristics, and the long-term practice of their application testifies to the reliability of these solutions. Numerical methods for calculating the bases are much more complicated, in most cases it is necessary to determine a larger number of characteristics (model parameters) of soils during surveys, and often their reliability has to be checked using analytical solutions. Due to the fact that compliance with regulatory requirements is still mandatory in the Russian Federation, we suggest using the appropriate analytical solutions provided in regulatory documents to solve practical problems of designing buildings and structures. At the same time, the structure of the proposed information technology allows us to apply numerical methods of solutions implemented in various programs such as PLAXIS, FLAC, etc.

Thus, BIMG uses two procedures for calculating the foundations. Classical solutions given in the previously mentioned SP and the finite element method. These calculations allow us to model the behavior of the foundations using various defining equations (soil models), including elastic behavior (in the case of using SP) and nonlinear models in finite element calculations. The second modeling procedure was successfully tested for various engineering and geological conditions when solving problems of calculating the settlement of foundations (Fig. 4), as well as the stability of the slopes. In both cases, the transition from the $3 \mathrm{D}$ model to the $2 \mathrm{D}$ model is used.

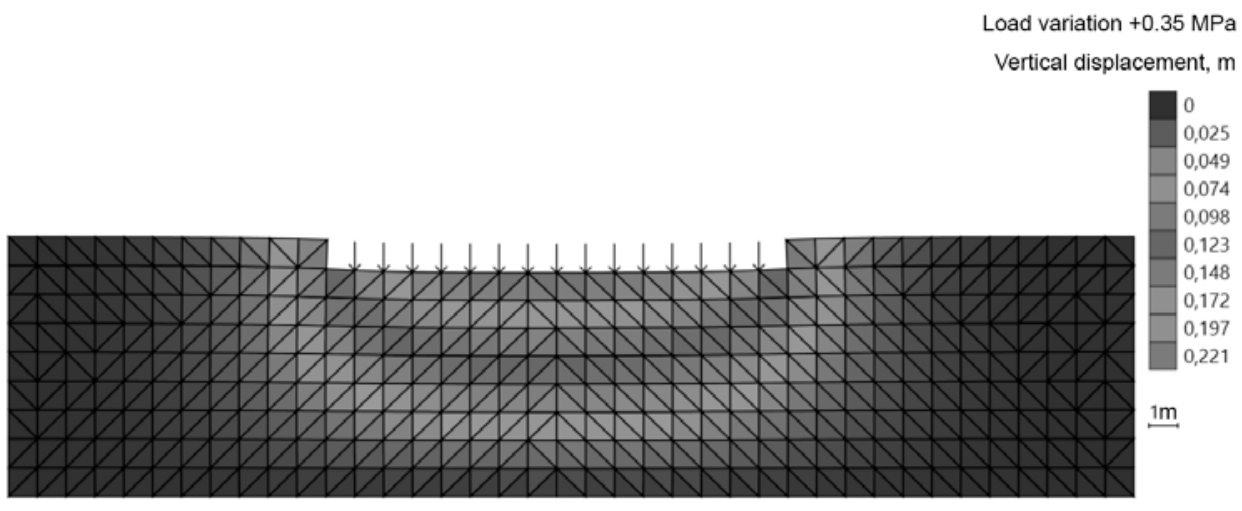

Fig. 4. 2D calculation of slab foundation settlement.

Estimation of the uncertainty of the properties of the $3 D$ model. In geotechnical studies, it is generally accepted practice (or should be) to assess possible errors in determining the lithology, physical and mechanical properties of soils and the impact of these errors on a building or structure under construction. This is sometimes called a hazard and risk analysis [7]. Various methodologies, such as geostatic methods and probabilistic studies, are used to give a certain quantitative assessment of possible errors in the design of an engineering structure due to uncertainty about the properties of soils. However, two very important main points - the geological and geotechnical expertise used to create the model, and the division of the soil mass into IGE are considered in these analyses only very superficially or not at all.

In the existing estimates of the uncertainty of soil properties, the probability of distribution or innate error in estimating properties in a certain place of space is well determined if appropriate statistical procedures are used. However, much depends on the correctness of the data, which in itself is related to (1) the geology and (2) the variations allowed for each of the geotechnical characteristics of soils.

In the technology under consideration, it is proposed to evaluate the uncertainty of soil properties by modeling the behavior of the reference foundation for various input 
characteristics of soils [8]. In this case, the sensitivity of the base-foundation-structure system (BFSS) is evaluated by introducing virtual workings between the existing standard ones and the subsequent calculation of settlement at the considered point of the foundation.

Such calculations can be performed on a variety of virtual workings with the determination of the average foundation settlement. If such variations lead to significant changes in the behavior of BFSS, then it is necessary to increase the volume of engineering and geological data due to additional workings, or to increase the reliability of the structure by increasing the strength of structures. This question is analyzed in the works [8,9] with the help of mathematical modeling and exact solutions for the standards (simplified models) of SOFS

Thus, the proposed approach of "sensitivity" analysis allows us to assess the degree of influence of each of the input parameters and the type of interpolation functions on the final result of the calculation. If traditional calculations gave only an average or pessimistic value, now you can find more information about possible variations in the results of calculations.

\section{Conclusion}

1. Digital processing of engineering-geological and geotechnical data leads to the fact that huge volumes of such data can be combined and analyzed, as well as imported and exported from databases and/or large spatial models in fractions of seconds. As a result, the assessment of the behavior of the designed buildings can be performed directly in the field during engineering and geological surveys.

2. Uniformity of data formats is important for the interoperability of data on various parameters and from various data sources. However, the use of large databases and the import of data sets into foundation calculation programs also require uniformity in the ways of structuring the description of geotechnical parameters and foundation structure

3. Time is almost never a parameter in $3 \mathrm{D}$ geotechnical models. If you enter time as a parameter of the model, then we are already talking about 4D modeling. This is fundamentally important when calculating the sediment of foundations in time and taking into account the creep of soils, as well as modeling the process of freezing and thawing of frozen and permafrost soils.

\section{References}

1. G. Morin, Hassall S., Chandler R., 2014. Case study - The real life benefits of Geotechnical Building Information Modelling. Proceedings of Information Technology in Geo-Engineering. D.G. Toll et al. (Eds.), pp. 95-102 (2014)

2. L. Xikui, Li.Yongfa., Sun Peipei. Study on Three Dimensional Modeling and Visualization in Geology. The Open Civil Engineering Journal. 10, pp. 114-124 (2016)

3. D. Migilinskas, Popov V., Juocevicius V., Ustinovichius L. The Benefits, Obstacles and Problems of Practical Bim Implementation. Procedia Engineering. 57, pp. .767774 (2013)

4. V. Nappa, Ventini R., Ciotta V., Domenico A. A new frontier of BIM process: Geotechnical BIM. Proceedings of the XVII ECSMGE-2019 Geotechnical engineering foundation of the future, pp. 1-7 (2019)

5. X. Pan, Chu J., Aung Z., Chiam K., Wu D. 3D Geological Modelling: A Case Study for Singapore. ICITG 2019: Information Technology in Geo-Engineering, pp. 161-167 (2019) 
6. T. Lunne., Robertson P.K., Powell, J.J.M. Cone penetration testing in geotechnical practice. Blackie Academic. Chapman-Hall Publishers, U.K.; available from EF Spon. Routledge Pub., New York, 312 p. (1997)

7. G. Shi G. Data Mining and Knowledge Discovery for Geoscientists, 371 p. (2014)

8. V.A. Barvashov, Boldyrev G.G. Sensitivity of structures and geological data. COMPDYN 20176th ECCOMAS Thematic Conference on Computational Methods in Structural Dynamics and Earthquake Engineering. M. Papadrakakis, M. Fragiadakis (eds.), Rhodes Island, Greece, 15-17 June 2017, pp. 1-11 (2017)

9. V.A. Barvashov, Boldyrev G.G. Soil Data Inflation in Analysis of Settlements and Tilts of Structures. 5th International Conference on Geotechnical and Geophysical Site Characterisation, 5-8 September, Australia, 2016, pp. 1-5 (2016) 